\title{
TÍNH SINH MIỄN DİCH CỦA VẮC XIN RUBELLA TRONG VẮC XIN PHỐI HỢP SỞI - RUBELLA (MRVAC) DO POLYVAC SẢN XUẤT
}

\begin{abstract}
Nguyễn Xuân Đông*, Đi
TÓM TẮT

Mục tiêu: Đánh giá tính sinh miễn dịch của vắc xin rubella trong vắc xin MRVAC. Đối tượng và phương pháp: Sử dưng thiết kế nghiên cứu thử nghiệm lâm sàng ngẩu nhiên có đối chứng, mù đơntrên 756 người từ 1 đến 45 tuổi tại hai tính Hà Nam và Hòa Bình, đo lường hiệu giá kháng thể kháng vi rút rubella bằng kĩ thuật EIA, phân tích các chỉ số để đánh giá tính sinh miễn dịch. Kết quả và kết luận: Ở nhóm chưa có kháng thể, tỉ lệ chuyển đối huyết thanh sau tiêm là $98,4 \%$ đến $99,3 \%$, hiệu giá kháng thể trung bình nhân (GMT) kháng vi rút rubella sau tiêm MRVAC là 32,00 EIA unit, thấp hơn có ý nghĩa so với nhóm đối chứng. Ở nhóm đã có kháng thể, GMT sau tiêm MRVAC là 49,87 EIA unit, tương đương so với trước tiêm và vắc xin đối chứng.
\end{abstract}

Tư khóa: Vắc xin MRVAC; Tính sinh miễn dịch, Vắc xin Rubella

\section{SUMMARY}

IMMUNOGENICITY OF RUBELA VACCINE OF MEASLES AND RUBELLA COMBINED VACCINE (MRVAC) MANUFACTERING BY POLYVAC

Objectives: To assess immunogenicity of rubella vaccine of MRVAC vaccine. Subjects and method: Randomized, controlled and single-blind clinical trial study was conducted on 756 people aged 1 to 45 years old in $\mathrm{Ha} \mathrm{Nam}$ and $\mathrm{Hoa}$ Binh provinces, measured rubella antibody titre by EIA technique, analysed indexes to evaluate immunogenicity. Results and conclusion: in negative antibody group, post-vaccination seroconversion rate was from $98.4 \%$ to $99.3 \%$, MRVAC post-vaccination geometric mean titre (GMT) was 32.00 EIA unit, significantly lower than control vaccine. In possitiveantibody group, MRVAC post-vaccination GMT was 49.87 EIA units, equivalent to pre-vaccination and control vaccine.

Keywords: MRVAC vaccine; Immunogenicity; Rubella vaccine

\section{I. ĐĂT VẤN ĐỀ}

Rubella là bệnh truyền nhiễm cấp tính, gây dịch. Nếu người mẹ nhiễm rubella trong 3 tháng đầu của thai kỳ có thể gây ra sảy thai, thai chết lưu, hội chứng rubella bẩm sinh (Congenital Rubella Syndrome) và nhiễm rubella bẩm sinh ở

*Viện Y học dự phòng Quân đội

** Học viện Quân y

***TTNCSX vắc Xin và sinh phẩm y tế

Chịu trách nhiệm chính: Nguyễn Xuân Đông

Email: nguyenxuandong81@gmail.com

Ngày nhận bài: $25 / 11 / 2020$

Ngày phản biên khoa học: 9/12/2020

Ngày duyệt bài: 18/12/2020 trẻ sơ sinh [1]. Ở nước ta, bệnh rubella vẫn gây ra hội chứng rubella bẩm sinh (CRS) hàng năm, tăng gánh nặng về y tế, kinh tế và xã hội [2]. Nhằm giảm chi phí trong chương trình tiêm chủng mở rông và chủ động kiểm soát, phòng chống rubella, Trung tâm Nghiên cứu sản xuất vắc xin và sinh phẩm $y$ tế (POLYVAC) đã sản xuất thành công vắc xin MRVAC theo chuyển giao công nghê từ Nhật Bản. Chúng tôi tiến hành nghiên cứu này nhằm: Đánh giá tính sinh miễn dịch của vắc xin rubella trong vắc xin MRVAC.

\section{II. ĐỐI TƯỢNG VÀ PHƯƠNG PHÁP NGHIÊN CỨU \\ 2.1.Đối tượng nghiên cứu}

2.1.1. Người tình nguyện. Tổng số 756 người ở hai tỉnh Hà Nam và Hòa Bình đã tham gia nghiên cứu, gồm 420 trẻ từ 1 đến 2 tuổi, 168 người trên 2 đến dưới 18 tuổi và 168 người từ 18 đến 45 tuổi. Trong số 756 người có 504 đối tượng được tiêm vắc xin nghiên cứu MRVAC và 252 đối tượng tiêm vắc xin đối chứng. Thời gian nghiên cứu: từ 08/04/2016 đến 27/07/2016.

\subsubsection{Vắc xin nghiên cứu}

Vắc xin thử nghiệm: Vắc xin MRVAC do POLYVAC sản xuất.

- Thành phần: Mỗi lọ 10 liều vắc xin được hồi chỉnh với $5,5 \mathrm{ml}$ nước pha tiêm. Mỗi liều $0,5 \mathrm{ml}$ bao gồm: Vi rút sởi sống, giảm độc lực chủng AIK-C $\geq 1000$ PFU

Vi rút rubella sống, giảm độc lực chủng

Takahashi $\geq 1000$ PFU

Chất ổn định: Lactose: $2 \%$

D-Sorbitol: 0,72\%

L-Sodium glutamate: $0,4 \%$

Hydrolized Gelatin: 0,36\%

Kháng sinh: Erythromycin: $\leq 12.5 \mu \mathrm{g}$

Kanamycin: $\leq 12.5 \mu \mathrm{g}$

- Lô số: MR-0115; Ngày sản xuất: 04/11/2015; Hạn dùng: 04/11/2017.

Vắc xin đối chứng: vắc xin $M R$ do Ấn Độ sản xuất. Lô số: 012N4072; Ngày sản xuất: 7/2014;Hạn dùng: 1/8/2016.

\subsection{Phương pháp nghiên cứu}

2.2.1.Thiết kế nghiên cứu. Sử dưng thiết kế nghiên cứu thử nghiệm lâm sàng ngẩu nhiên, có đối chứng, mù đơn.

Mẫu máu $M 0$ được lấyngay trước khi tiêm vắc xin, mẫu M1 lấy sau tiêm 42-56 ngày để định lượng kháng thể kháng vi rút rubella trước và 
sau tiêm (hình 1). Các mẫu máu M0, M1 sau khi được lấy tại trạm xá xã được chuyển về Trung tâm $Y$ học dự phòng tỉnh Hà Nam và Trung tâm $y$ tế dự phòng huyện Kim Bôi để tiến hành ly tâm tách huyết thanh, mẫu huyết thanh sau đó được chuyển về Phòng Miễn dịch vắc xin, Khoa Miễn dịch và sinh học phân tử, Viện Vệ sinh Dịch tễ Trung ương để định lượng kháng thể bằng kĩ thuật xét nghiệm phản ứng miễn dịch enzyme (EIA), quy đổi đơn vị quốc tế với công thứcgiá trị EIA x 2,3 = Đơn vị quốc tế/ml $(\mathrm{IU} / \mathrm{ml})$.

\section{Tiêm vắc xin}

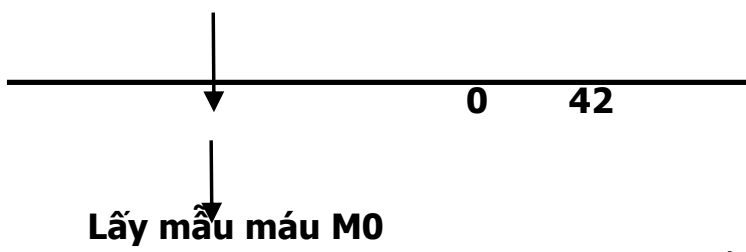

56

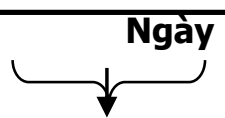

Lấy mẫu máu M1

Hình 1. Sơ đồ tiêm vắc xin và lây máu xét nghiệm

Tổng số 756 đối tượng đã được lấy máu lần thứ nhất, nhưng khi tiến hành thu thâp mẫu máu M1 thì có 23 đối tượng rút khỏi nghiên cứu bao gồm: 2 trường hợp trùng mã huyết thanh, 21 trường hợp gồm cả không đồng ý lấy máu lần 2 và một số rời khỏi nơi cư trú nên không tham gia được (mặc dù các đối tượng này đã cam kết khổng rời địa phương trong vòng 2 tháng trước khi vào nghiên cứu) nên chỉ còn 733 mẩu máu được định lượng kháng thể sau tiêm.

Tính sinh miễn dịch của vắc xin rubellađược đánh giá bằng các chỉ số chính: tỉ lệ chuyển đổi huyết thanh, sự gia tăng hiệu giá kháng thể (HGKT), hiệu giá kháng thể trung bình nhân (GMT) trước và sau tiêm giữa các nhóm nghiên cứu, theo từng nhóm tuổi.

\subsubsection{Vấn đề đạo đức trong nghiên cứu}

Nghiên cứu này tuân thủ đúng theo các nguyên tắc đạo đức của "Tuyên bố Helsinki" và các phiên bản sửa đổi cũng như quy định hiện hành của Bộ $Y$ tế về "Thực hành tốt thử thuốc trên lâm sàng".

\section{KẾT QUẢ NGHIÊN CỨU VÀ BÀN LUÂ̂N}

\subsection{Nhóm chưa có kháng thể kháng vi rút rubella trước tiêm}

Bảng 1. Tỉ lệ chuyển đổi huyết thanh theo nhóm tuổi và nhóm nghiên cứu

\begin{tabular}{|c|c|c|c|c|c|c|c|}
\hline \multirow{2}{*}{ Nhóm tuổi } & \multicolumn{3}{|c|}{ MRVAC } & \multicolumn{3}{c|}{ Nhóm đối chứng } & \multirow{2}{*}{ p } \\
\cline { 2 - 8 } & $\mathbf{n}$ & SL & $\mathbf{0}$ & $\mathbf{n}$ & $\mathbf{S L}$ & $\mathbf{\%}$ & 0,524 \\
\hline Tữ 1-2 tuối & 258 & 254 & 98,4 & 129 & 128 & 99,2 & 0,5 \\
\hline Trên 2-dưới 18 tuối & 7 & 7 & 100 & 5 & 5 & 100 & \\
\hline Tứ 18-45 tuối & 6 & 6 & 100 & 6 & 6 & 100 & \\
\hline Tính chung & 271 & 267 & 98,5 & 140 & 139 & 99,3 & 0,504 \\
\hline
\end{tabular}

Tỉ lệ chuyển đổi huyết thanh tính chung 3 nhóm và ở nhóm từ 1-2 tuổi (trong cả 2 nhóm thứ nghiệm và đối chứng) đều rất cao từ 98,4\% (96,9\% - 100\%) đến 99,3\% (97,9\% - 100\%). Sự khác biệt không có ý nghĩa thống kê ( $p>0,05$, Chi-square test). Số trường hợp âm tính với kháng thể kháng vi rút rubella trước tiêm ở hai nhóm tuổi còn lại rất thấp và tất cả các trường hợp này sau tiêm đều có chuyển đổi huyết thanh. Tỉ lệ này trong nghiên cứu của chúng tôi tương đươnng với nghiên cứu của Takeuchi Y $(96,7 \%)[3]$.

Bảng 2. Hiệu giá trung binh nhân của kháng thể kháng vi rút rubella sau tiêm theo nhóm tuổi và nhóm nghiên cứu

\begin{tabular}{|c|c|c|c|c|}
\hline Nhóm tuối & & MRVAC & Đối chứng & p \\
\hline \multirow{3}{*}{$\begin{array}{c}\text { Từ } 1 \text { đến } 2 \\
\text { tuổi }\end{array}$} & $\mathrm{n}$ & 258 & 129 & \multirow{3}{*}{0,001} \\
\hline & $\log _{2}$ GMT $(95 \%$ CI) & $5,02(4,91-5,14)$ & $5,70(5,58-5,81)$ & \\
\hline & GMT $(95 \%$ CI $)$ & $32,45(30,06-35,26)$ & $51,98(47,84-56,10)$ & \\
\hline \multirow{3}{*}{$\begin{array}{l}\text { Trên } 2 \text { đênn } \\
\text { dưới } 18 \text { tuổi }\end{array}$} & $\mathrm{n}$ & 7 & 5 & \\
\hline & $\log _{2}$ GMT $(95 \%$ CI $)$ & $4,90(4,30-5,51)$ & $5,87(5,62-6,12)$ & \\
\hline & GMT(95\% CI) & $29,86(19,70-45,57)$ & $58,49(49,18-69,55)$ & \\
\hline \multirow{3}{*}{$\begin{array}{c}\text { Từ } 18 \text { đến } \\
45 \text { tuổi }\end{array}$} & $\mathrm{n}$ & 6 & 6 & \\
\hline & $\log _{2}$ GMT $(95 \%$ CI) & $4,03(3,19-4,86)$ & $5,43(5,10-5,76)$ & \\
\hline & GMT $(95 \%$ CI $)$ & $16,34(9,13-29,04)$ & $43,11(34,30-54,19)$ & \\
\hline
\end{tabular}




\begin{tabular}{|c|c|c|c|c|}
\hline \multirow{3}{*}{ Tính chung } & $\mathrm{n}$ & 271 & 140 & \multirow{2}{*}{0,001} \\
\cline { 2 - 4 } & $\log _{2} \mathrm{GMT}(95 \% \mathrm{CI})$ & $5,00(4,88-5,11)$ & $5,69(5,59-5,80)$ & \\
\cline { 2 - 5 } & $\mathrm{GMT}(95 \% \mathrm{CI})$ & $32,00(29,45-34,54)$ & $51,63(48,17-55,72)$ & \\
\hline
\end{tabular}

Log $_{2}$ HGKT rubella sau tiêm tính chung và nhóm 1-2 tuổi ở cả hai nhóm nghiên cứu đều không tuân theo luật phân phối chuẩn ( $p<0,05$, Kolmogorov-Smirnov test). Log $_{2}$ GMT sau tiêm ở nhóm nghiên cứu thấp hơn có ý nghĩa so với nhóm đối chứng ( $p<0,05$, Mann-Whitney test). Không có sự tương quan giữa HGKT rubella sau tiêm với tuổi của đối tượng nghiên cứu chưa có kháng thể trước tiêm với hệ số $r=-0,020$ ( $p=$
0,683 , Spearman). Ngoại trừ chủng RA 27/3 (có trong vắc xin đối chứng) có đáp ứng miễn dịch gần giống thì các chủng rubella vắc xin khác thường chỉ tạo hiệu giá kháng thể đạt mức từ $1 / 4$ đến $1 / 8$ so với nhiễm vi rút hoang dại, do đó chủng rubella Takahashi của vắc xin MRVAC tao hiệu giá kháng thể thấp hơn chủng RA 27/3 của vắc xin đối chứng [4].

\subsection{Nhóm có kháng thể kháng rubella trước tiêm}

Bảng 3. Hiệu giá trung bình nhân của kháng thể kháng vi rút rubella trước và sau tiêm ở hai nhóm nghiên cứu

\begin{tabular}{|c|c|c|c|c|c|}
\hline & \multicolumn{2}{|c|}{ MRVAC } & \multicolumn{2}{|c|}{ Đối chứng } & \multirow[b]{2}{*}{$\mathbf{p}$} \\
\hline & $\begin{array}{l}\text { TTiêm (1) } \\
(n=458)\end{array}$ & $\begin{array}{l}\text { STiêm (2) } \\
(n=458)\end{array}$ & $\begin{array}{l}\text { TTiêm (3) } \\
(n=234)\end{array}$ & $\begin{array}{l}\text { STiêm (4) } \\
(\mathrm{n}=234)\end{array}$ & \\
\hline $\begin{array}{l}\log _{2} \mathrm{GMT} \\
(95 \% \mathrm{CI})\end{array}$ & $\begin{array}{c}4,52 \\
(4,42-4,61)\end{array}$ & $\begin{array}{c}5,55 \\
(5,49-5,60)\end{array}$ & $\begin{array}{c}4,58 \\
(4,44-4,73)\end{array}$ & $\begin{array}{c}5,14 \\
(5,03-5,24)\end{array}$ & $\begin{array}{l}(1,2): 0,001 \\
(3,4): 0,001\end{array}$ \\
\hline $\begin{array}{c}\text { GMT } \\
(95 \% \mathrm{CI}) \\
\end{array}$ & $\begin{array}{c}22,94 \\
(21,41-24,42)\end{array}$ & $\begin{array}{c}46,85 \\
(44,94-48,50)\end{array}$ & $\begin{array}{c}23,92 \\
(21,71-26,54)\end{array}$ & $\begin{array}{c}35,26 \\
(32,67-37,79)\end{array}$ & $\begin{array}{l}(1,3): 0,382 \\
(2,4): 0,001\end{array}$ \\
\hline
\end{tabular}

GMT kháng thể kháng vi rút rubella trước và sánh ghép cặp trước-sau tiêm thì nhóm MRVAC sau tiêm MRVAC đều là 49,87 EIA unit $(114,70)$, còn nhóm đối chứng lần lượt là 49,18 EIA unit $(113,11 \mathrm{IU} / \mathrm{ml})$ và $56,49 \mathrm{EIA}$ unit $(129,93 \mathrm{IU} / \mathrm{ml})$. Khi so sánh GMT trước và sau tiêm giữa nhóm MRVAC và đối chứng thì không cho thấy sự khác biệt nhưng đánh giá đáp ứng miễn dịch bẳng so không cho thấy sự gia tăng GMT sau tiêm, trong khi nhóm đối chứng cho thấy sự gia tăng có ý nghĩa thống kê. Điều đó chứng tỏ vắc xin MRVAC tạo đáp ứng miễn dịch với nhóm có kháng thể kháng vi rút rubella trước tiêm thấp hơn nhóm đối chứng.

Bảng 4. Mức độ gia tăng hiệu giá kháng thể kháng vi rút rubella sau tiêm theo nhóm tuổi và nhóm nghiên cứu

\begin{tabular}{|c|c|c|c|c|c|c|c|c|}
\hline \multirow{2}{*}{$\begin{array}{c}\text { Nhóm } \\
\text { tuổi }\end{array}$} & \multirow{2}{*}{$\begin{array}{c}\text { HGKT } \\
\text { STiêm/TTiêm }\end{array}$} & \multicolumn{3}{|c|}{ MRVAC } & \multicolumn{3}{|c|}{ Đối chứng } & \multirow[b]{2}{*}{$\mathbf{p}$} \\
\hline & & $\mathbf{n}$ & $\mathbf{S L}$ & $\%$ & $\mathbf{n}$ & $\mathbf{S L}$ & $\%$ & \\
\hline \multirow{3}{*}{$\begin{array}{l}\text { Từ 1-2 } \\
\text { tuổi }\end{array}$} & $<1$ lần & \multirow{3}{*}{9} & 4 & 44,4 & \multirow{3}{*}{7} & 3 & 42,9 & \multirow{3}{*}{0,635} \\
\hline & $1-<2$ lần & & 4 & 44,4 & & 4 & 57,1 & \\
\hline & > 2 lần & & 1 & 11,2 & & 0 & 0 & \\
\hline \multirow{3}{*}{$\begin{array}{c}\text { Trên 2- } \\
\text { dưới } 18 \\
\text { tuối }\end{array}$} & $<1$ lần & \multirow{3}{*}{104} & 59 & 56,7 & \multirow{3}{*}{48} & 17 & 35,4 & \multirow{3}{*}{0,004} \\
\hline & $1-<2$ lần & & 45 & 43,3 & & 28 & 58,4 & \\
\hline & > 2 lần & & 0 & 0 & & 3 & 6,2 & \\
\hline \multirow{3}{*}{$\begin{array}{l}\text { Từ 18-45 } \\
\text { tuổi }\end{array}$} & $<1$ lần & \multirow{3}{*}{104} & 50 & 48,0 & \multirow{3}{*}{50} & 12 & 24,0 & \multirow{3}{*}{0,011} \\
\hline & $1-<2$ lần & & 53 & 51,0 & & 36 & 72,0 & \\
\hline & > 2 lần & & 1 & 1,0 & & 2 & 4,0 & \\
\hline \multirow{3}{*}{$\begin{array}{l}\text { Tính } \\
\text { chung }\end{array}$} & $<1$ lần & \multirow{3}{*}{217} & 113 & 52,1 & \multirow{3}{*}{105} & 32 & 30,5 & \multirow{3}{*}{0,001} \\
\hline & $1-<2$ lần & & 102 & 47,0 & & 68 & 64,7 & \\
\hline & > 2 lần & & 2 & 0,9 & & 5 & 4,8 & \\
\hline
\end{tabular}

Ở cả hai nhóm nghiên cứu, HGKT sau tiêm/trước tiêm tăng từ 2 lần trở lên chiếm rất ít với lần lượt 0,9 và $4,8 \%$, chỉ có 1 trường hợp ở nhóm đối chứng tăng trên 4 lần, tỉ lệ chuyển đổi huyết thanh lần lượt là 0 và $1 \%$, đa số đều gia tăng mức độ nhẹ từ 1 đến dưới 2 lần hoặc suy giảm HGKT. Phẩn tích chung, theo các nhóm trên 2 đến dưới 18 tuổi, từ 18 đến 45 tuổi và theo giới tính cho thây tỉ lệ suy giảm HGKT ở nhóm MRVAC cao hơn nhưng tỉ lệ gia tăng HGKT thấp hơn so với nhóm đối chứng, sự khác biệt có ý nghĩa thống kê. Vắc xin MRVAC không cho thấy sự gia tăng hiệu giá kháng thể còn vắc xin đối chứng tăng hiệu giá mức độ nhẹ.

Các vắc xin rubella thông thường không tạo đáp ứng miễn dịch sau liều tăng cường mạnh mẽ 
như vắc xin sởi. Các trường hợp suy giảm HGKT sau tiêm so với trước tiêm do yếu tố thời gian, kèm theo sử dụng trong trung hòa vi rút của vắc xin và không tạo đáp ứng miễn dịch.Vắc xin MRVAC cho kêt quả khá tốt ở nhóm chưa có kháng thể trước tiêm với tỉ lệ chuyển đổi huyết thanh rất cao, cải thiện rõ rệt tỉ lệ có kháng thể sau tiêm, những chỉ số này tương đương với vắc xin đối chứng, tuy nhiên GMT sau tiêm thấp hơn nhiều chủng rubella ở các nghiên cứu khác. Tuy vắc xin MRVAC không tạo đáp ứng miễn dịch với nhóm có kháng thể kháng vi rút rubella trước tiêm như vắc xin đối chứng nhưng hiện tại thì sự cần thiết của liều tăng cường rubella cũng chưa được chứng minh, thời gian tồn lưu của kháng thể kháng vi rút rubella sau tiêm chủng rất dài bất chấp sự sự giảm của HGKT, tỉ lệ có kháng thể của quần thể luôn giữ rất cao qua hàng chục năm nên điều này không thật sự quan trọng [4],[5].

\section{KẾT LUẬN}

Vắc xin MRVAC đạt yêu cầu về tính sinh miễn dịch với vi rút rubella, cụ thể: ở nhóm chưa có miễn dịch với rubella trước tiêm vắc xin, tỉ lệ chuyển đối huyết thanh sau tiêm là $98,4 \%$ (96,9\%-100\%) đến 99,3\% (97,9\%-100\%), hiệu giá kháng thể trung bình nhân (GMT) kháng vi rút rubella sau tiêm MRVAC là 32,00 EIA unit, thấp hơn có ý nghĩa so với nhóm đối chứng. Ớ nhóm đã có kháng thể, GMT sau tiêm MRVAC là 49,87 EIA unit, tương đương so với trước tiêm và vắc xin đối chứng.

\section{TÀI LIỆU THAM KHẢO}

1. Susan E. Reef, Stanley A. Plotkin (2017), "Rubella Vaccines", Plotkin's Vaccines,7th edition, Elsevier, Philadelphia, USA: 970-1000.

2. Trân Như Dương, Vũ Hải Hà, Phạm Quãang Thái và cs (2016), "Một số đặc điểm dịch tễ hội chứng rubella bẩm sinh được giám sát tai Bênh viện Nhi Trung ương, 2011-2016", Tạp chí Y học dự phòng, 10(183): 35-42.

3. Takeuchi $Y$, Togashi $T$, Sunakawa $K$ et al (2002), "Field trial of combined measles and rubella live attenuated vaccine", Infectious disease magazine, 76(1), pp.56-62.

4. WHO (2008), The Immunological Basis for Immunization Series. Module 11: Rubella 2008.

5. Susan E. Reef, Stanley A. Plotkin (2017), "Rubella Vaccines", Plotkin's Vaccines,7th edition, Elsevier, Philadelphia, USA: 970-1000.

\section{KẾT QUẢ ĐIỀU TRỊ CAN THIỆP NÚT PHÌNH ĐộNG MẠCH SỐNG - NỀN TẠI BỆNH VIỆN NHÂN DÂN 115}

\section{TÓM TẮT}

Mục tiêu: Đánh giá kết quả điều trị can thiêp nút phình động mạch sống - nền trong điêu trị đột quy. chảy máu khoang dưới nhện do võ̃ phình động mạch sống - nền. Đối tượng và phương pháp: Nghiên cứu tiến cứu, mở, cắt ngang, không đối chứng có theo dõi dọc trên 51 bệnh nhân đột quy chảy máu điều trị nội trú tại bệnh viện Nhân dân 115, từ 1/2014 đến 12/2018. Kết quả: Có $80,39 \%$ túi phình được can thiệp gây tắc hoàn toàn và $13,72 \%$ túi phình được gây tắc bán phần và tái võ̃ phình sau can thiệp là 5,89\%. Đa số các bệnh nhân có điểm GOS là 5 lúc ra viện chiếm $72,56 \%$. Thang điểm Rankin sửa đổi khi ra viện, chủ yếu có Rankin 1 điểm chiếm 47,06\%. Kiểm tra GOS sau 3 tháng mức tốt chiếm 20,45\%; sau 6

\footnotetext{
${ }^{1}$ Trường Đại học Y khoa Phạm Ngọc Thạch ${ }^{2}$ Hoc viên Quần $Y$

Chịu trách nhiệm chính: Tống Đức Minh

Email: minhhoa142@gmail.com

Ngày nhận bài: 25/11/2020

Ngày phản biện khoa học: 10/12/2020

Ngày duyệt bài: 19/12/2020
}

Phùng Quốc Thái ${ }^{1}$, Phạm Ngọc Hoa ${ }^{1}$,
Bùi Quang Tuyển ${ }^{2}$, Tống Đức Minh ${ }^{2}$

tháng $(22,73 \%)$; sau 12 tháng điểm GOS mức tốt chiếm $65,91 \%$. Kết quả kiểm tra hình ảnh tỷ lệ tái thông sau ra viện 3 tháng chiếm 4,55\%; sau 6 tháng $(6,82 \%)$; sau 12 tháng, tái thông chiếm $18,18 \%$. Kết luận: Chủ yếu các túi phình được xử trí gây tắc hoàn toằn. Lúc ra viện, đa số bệnh nhân có GOS là 5 và Rankin sửa đổi là 1 điểm. Kết quả tái thông sau can thiệp động mạch dưới $20 \%$.

Tư khóa: Điều trị can thiệp nút động mạch, phình động mạch sống - nền.

\section{SUMMARY}

RESULTS OF INVASIVE TREATMENT TO CLOG ANEURYSMS OF VERTEBROBASILAR

\section{ARTERY AT PEOPLE'S HOSPITAL 115}

Objective: To evaluate the treatment results of intervention to clog aneurysms of vertebrobasilar artery in the treatment of subarachnoid haemorrgic stroke due to the bursted aneurysms of vertebrobasilar artery. Subjects and methods: A prospective, open, cross-section, non-controlled study with vertical follow-up of 51 haemorrgic stroke patients treated inpatient at People's Hospital 115, from $1 / 2014$ to $12 / 2018$. Results: $80.39 \%$ of the 